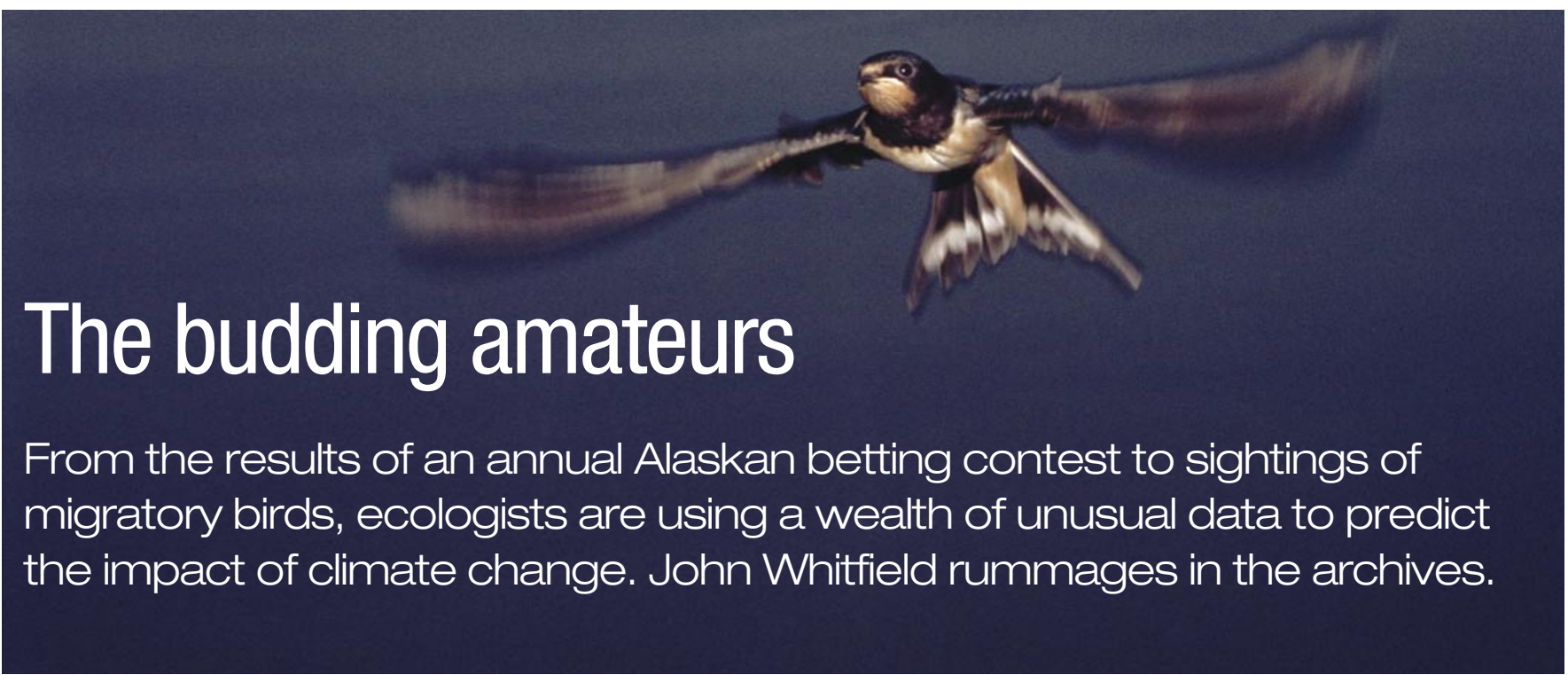

$\mathrm{T}$ im Sparks slides a small leatherbound notebook out of an envelope. The book's yellowing pages contain beekeeping notes made between 1941 and 1969 by the late Walter Coates of Kilworth, Leicestershire. He adds it to his growing pile of local journals, birdwatchers' lists and gardening diaries. "We're uncovering about one major new record each month," he says, "I still get surprised."

Around two centuries before Coates,

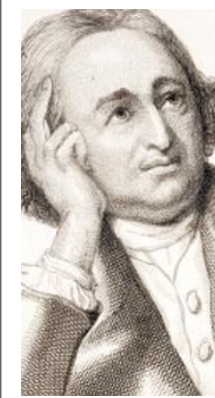
Robert Marsham, a landowner from Norfolk in the east of England, began recording the life cycles of plants and animals on his estate - when the first wood anemones flowered, the dates on which the oaks burst into leaf and the rooks began nesting. Successive Marshams contin-

Taking note: ued compiling these notes Robert Marsham. for 211 years ${ }^{1}$.

Today, such records are being put to uses that their authors could not possibly have expected. These data sets, and others like them, are proving invaluable to ecologists interested in the timing of biological events, or phenology. By combining the records with climate data, researchers can reveal how, for example, changes in temperature affect the arrival of spring, allowing ecologists to make improved predictions about the impact of climate change.

A small band of researchers is combing through hundreds of years of records taken by thousands of amateur naturalists. And more systematic projects have also started up, producing an overwhelming response. "The amount of interest is almost frightening," says Sparks, a climate researcher at the Centre for Ecology and Hydrology in Monks Wood, Cambridgeshire.

Sparks first became aware of the army of "closet phenologists", as he describes them, when a retiring colleague gave him the Marsham records. He now spends much of his time following leads from one historical data set to another.

As news of his quest spreads, people tip him off to other historical records, and more amateur phenologists come out of their closets. The British devotion to recording and collecting makes his job easier — one man from Kent sent him 30 years' worth of kitchen calendars, on which he had noted the date that his neighbour's magnolia tree flowered.

\section{Changing times}

Other researchers have unearthed data from equally odd sources. Rafe Sagarin, an ecologist at Stanford University in California, recently studied records of a betting contest in which participants attempt to guess the exact time at which a specially erected wooden tripod will fall through the surface of a thawing river. The competition has taken place annually on the Tenana River in Alaska since 1917, and analysis of the results showed that the thaw now arrives five days earlier than it did when the contest began ${ }^{2}$.

Overall, such records have helped to show that, compared with 20 years ago,

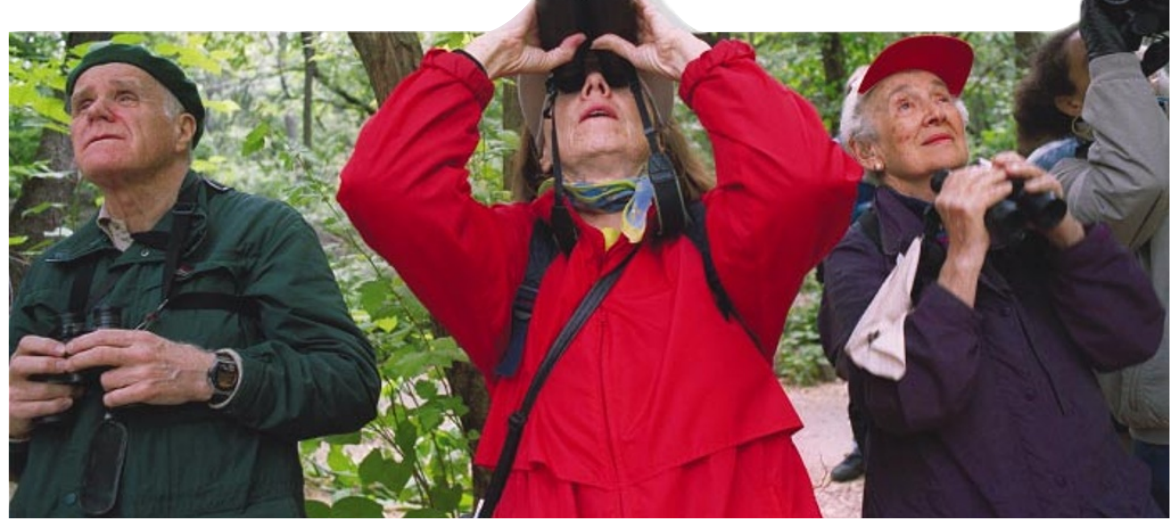

Well spotted: large-scale surveys, such as on bird migration, rely on data collected by volunteers. a raft of natural events now occur earlier across much of the northern hemisphere, from the opening of leaves to the return of birds from migration and the emergence of butterflies from hibernation. The data can also hint at how nature will change in the future. Hawthorn trees, for example, flower about 10 days earlier for every degree of warming, compared with between three and four days for hazel ${ }^{3}$.

Together with models of climate change, amateurs' records could help guide conservation. Terry Root, an ecologist at the University of Michigan in Ann Arbor, has taken between 1955 and 1996 on seasonal ponds in the American Midwest and combined them with climate data and models of future warming. Her analysis shows that the increased droughts that the models predict could halve the breeding populations at the ponds ${ }^{4}$. "The number of waterfowl in North America will most probably drop significantly with global warming," she says.

But not all professionals are happy to use amateur data. "A lot of scientists won't touch them, they say they're too full of prob-

lems," says Root. Bias can arise in a variety of ways. "When the collected birdwatchers' counts of wildfowl 


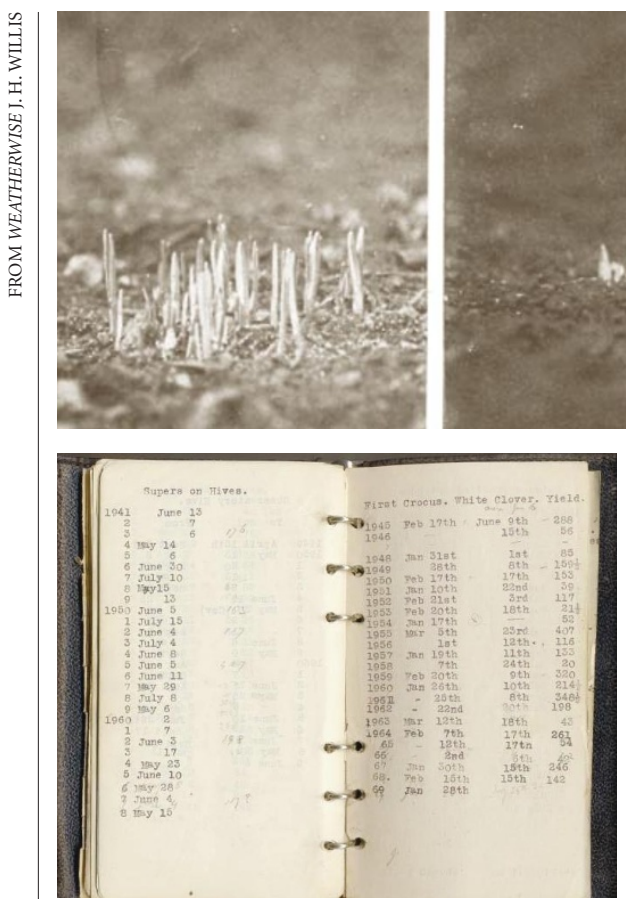

weather gets good, people go outside, and they tend to see things that they don't see when the weather is bad," says ecologist Marcel Visser of the Netherlands Institute of Ecology in Heteren. He advocates comparing data sets, saying that only when several independent records say the same thing can you believe them.

Different observers can also have different ideas of what constitutes, for example, an open snowdrop. "The biggest concern with ad hoc observations is how carefully and systematically they were taken," says Mark Schwartz of the University of Wisconsin, Milwaukee, who studies the interactions between plants and climate. "We need to know pretty precisely what a person's been observing - if they just say'I noted when the leaves came out', it might not be that useful." Measuring the onset of autumn can be particularly problematic because deciding when leaves change colour is a more subjective process than noting when they appear.

Phenological data also need careful analysis because of the small discrepancy between the length of the calendar year and the actual time between successive vernal equinoxes - the points in spring at which day and night are of equal length. Although the difference is only around a hundredth of a day, it can, over time, introduce biases into calendar-based measurements, as Sagarin explains on page 600 of this issue ${ }^{5}$.

Others caution that the mechanisms that link temperature and timing may not be straightforward. John Worrall, a forestry researcher at the University of British Columbia in Vancouver, points out that warmer weather may not necessarily delay autumn. Leaves age, and Worrall suggests that hotter summers could accelerate this
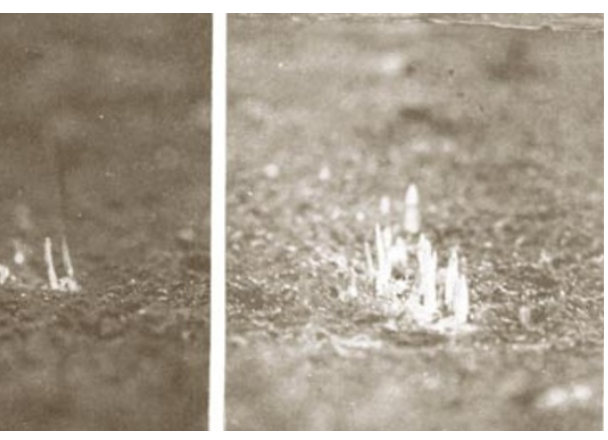

On the record: the same snowdrop clump captured every New Year's Day from 1922, and Walter Coates' beekeeping records (left).

process, causing them to fall earlier. $\mathrm{He}$ advocates a more involved approach than simply noting dates ${ }^{6}$, including measuring growth at the cellular level.

Plus, says Worrall, data for at least 50 years are needed before climate changes can be detected amid the natural variability. "I've been recording the daffodils in my backyard for 30 years, and I don't see any trend," he says. "The year-to-year variation is extraordinarily large: it's a mountain range.” Sparks, in contrast, says that trends can emerge in as little as a decade in records of species that are very sensitive to temperature, such as hawthorn or some butterflies, and that 20 years is often a useful minimum.

\section{Every note counts}

Overall, most phenologists are positive about the contribution that amateurs can make. "They get at the raw power of science: careful observation of the natural world," says Sagarin. But the professionals also acknowledge the need for careful quality control. Root, for example, tries to gauge the quality of an amateur archive by interviewing its collector. "You always have to worry - things as trivial as vacations can affect measurement. I disregard a lot of records because they're not rigorous enough," she says.

Others suggest that the right statistics can iron out some of the problems with amateur data. Together with colleagues at Wageningen University in the Netherlands, environmental scientist Arnold van Vliet is developing statistical techniques to account for the uncertainty in amateur phenological data.

With the enthusiasm of amateur phenologists evident from past records, professional researchers are now trying to create standardized recording schemes for future efforts. They hope that well-designed studies will generate a volume of observations large enough to drown out the idiosyncrasies of individual recorders. The data are cheap to collect, and can provide breadth in space, time and range of species. "It's very difficult to collect data on a large geographical scale without enlisting an army of observers," says Root.
In collaboration with the Woodland Trust, a British conservation charity, the Centre for Ecology and Hydrology has created the Nature's Calendar project to coordinate amateur phenologists. Launched last spring, the network started with 300 observers. Thanks to publicity gained from Today, a British current-affairs radio programme, this autumn 10,000 volunteers recorded the last date on which they mowed their lawns, when leaves fell from trees, and the arrival of winter migrant birds.

The European Union is funding the European Phenology Network (EPN), based at Wageningen University, to promote cooperation between national phenological networks and to act as a clearing house for data. When the Dutch radio programme Vroege Vogels (The Early Bird) heard about the EPN it contacted van Vliet, the network's coordinator, and launched a drive to sign up volunteer observers. Two thousand people have been corralled into noting, among other things, when swifts arrive and ox-eye daisies flower. A torrent of existing records has also been released. This week, delegates at an EPN-organized conference in Wageningen are discussing how to standardize the measurements taken by the different European networks.

Phenology also helps to drive home messages about climate change. "Because the public understand these records, they accept them," says Sparks. It can also illustrate potentially unpleasant consequences, he adds, such as the finding that more rat infestations are reported to local councils in warmer years. And getting people involved is great for public relations. "People are thrilled to think that the data they've been collecting as a hobby can be used for something scientific — it empowers them," says Root.

Mary Manning is one such newly empowered observer. On Christmas Day she will go into her garden in Norwich, England, and record which species are flowering — just as she has every year since 1963. Manning, a retired schoolteacher, is surprised but delighted that researchers are interested in her records: "I did it because I loved doing it".

John Whitfield works in Nature's science writing team.

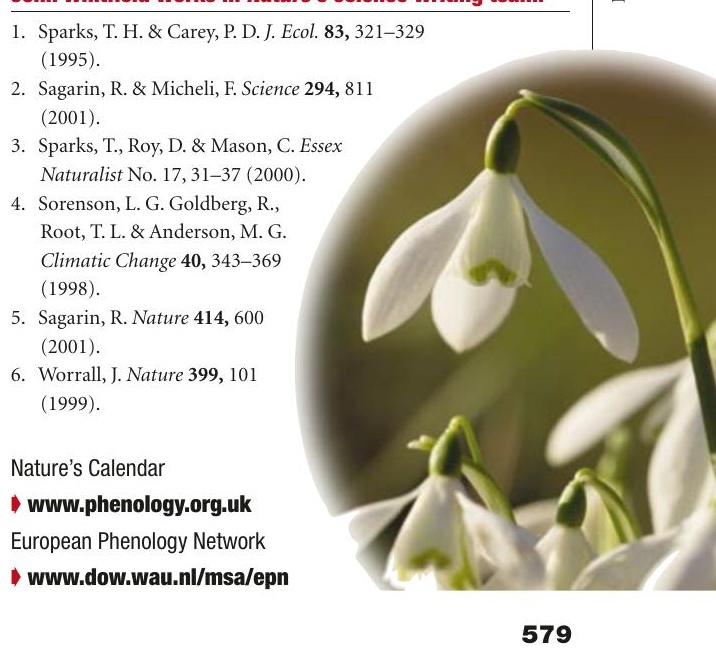

